\title{
Intracranial haemangiopericytoma: a rare case presenting with haemorrhage
}

\author{
Mohamed Abdelsadg, ${ }^{1}$ Avinash Kumar Kanodia, ${ }^{2}$ Colin Smith, ${ }^{3}$ Eric Ballantyne, \\ Khaled Patran ${ }^{1}$
}

${ }^{1}$ Neurosurgery, Ninewells Hospital, Dundee, UK ${ }^{2}$ Radiology, Ninewells Hospital, Dundee, UK

${ }^{3}$ NHS Lothian, Edinburgh, UK

\section{Correspondence to} Dr Avinash Kumar Kanodia, avinash.kanodia@nhs.net, avinash.kanodia@nhs.net

Accepted 2 March 2018
A) Check for updates

To cite: Abdelsadg $M$, Kanodia AK, Smith C, et al. BMJ Case Rep Published Online First: [please include Day Month Year]. doi:10.1136/bcr-2018224351

\section{DESCRIPTION}

Haemangiopericytomas (HPCs) are rare intracranial tumours. Until 1993 HPC was considered as an angioplastic variant of meningioma. ${ }^{1}$ The recently published WHO classification of central nervous system (CNS) tumours classifies HPCs as mesenchymal non-meningothelial tumours combined with solitary fibrous tumours (SFTs), graded $1-3$, and it is likely that this nomenclature will further evolve in the future. ${ }^{2}$ While these are highly vascular tumours, they often present with mass effect. Presentation with haemorrhage is also well described, but not commonly seen in clinical practice; this is partly due to the rarity of these tumours. ${ }^{3}$ This is only the 14 th case presenting with intracranial haemorrhage and only the second case presenting with haemorrhage in the posterior fossa.

A 58-year-old right-handed woman, without significant medical history, presented with suddenonset occipital headache. Initially she was fully conscious with no neurological deficits, but her clinical status deteriorated quickly, with increasing headache, nausea, vomiting and neck stiffness. She stopped smoking 28 years ago and was not known to be hypertensive, with no history of ischaemic heart disease or trauma. Her Glasgow Coma Scale score deteriorated quickly from 15 to 9 . She developed mild left-sided weakness (grade 4 in the upper/lower limb). A non-contrast CT head showed an acute intraparenchymal haematoma in the posterior fossa on the right side with associated mass effect and hydrocephalus. An area of lower attenuation within the acute haemorrhage was noted, raising the possibility of an underlying mass lesion (figure 1). An attempted contrast study failed

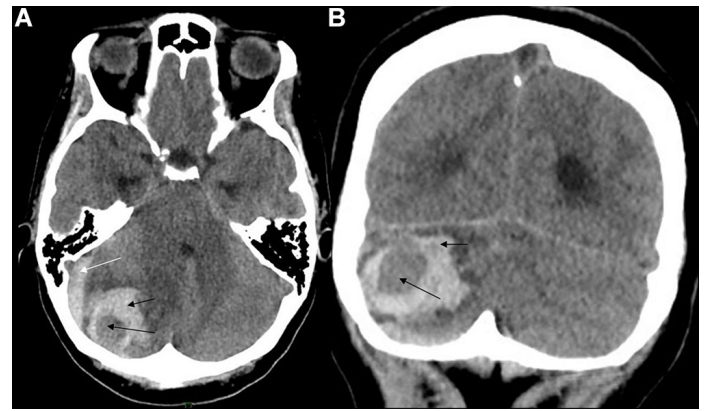

Figure 1 Initial non-contrast CT scan. (A) and (B) showing haematoma (small black arrows) with a lowdensity component (large black arrow) suspicious of an underlying mass. A subdural haematoma (white arrow) is also present.

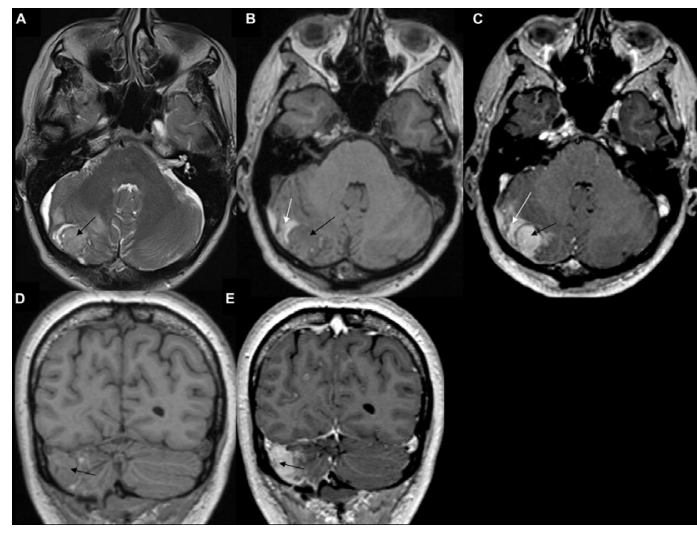

Figure 2 Initial postoperative MRI: (A) T2-weighted, $(B, C)$ T1 precontrast and postcontrast axial, and $(D, E)$ precontrast and postcontrast coronal images. Mass lesion (black arrows) in (A,B,D) showing homogeneous enhancement in $(C, E)$. Residual haematoma (white arrows in $\mathrm{B}, \mathrm{C})$.

due to extravasation and could not be repeated due to worsening clinical condition. A differential of tumours, commonly presenting with haemorrhage including metastasis and glioblastoma, was considered. She underwent insertion of occipital external ventricular drain (EVD) to relieve the hydrocephalus, followed by posterior fossa craniotomy and evacuation of cerebellar haematoma. Intraoperatively, suspicious tissue in the evacuated cavity was identified and samples were taken for histopathological analysis.

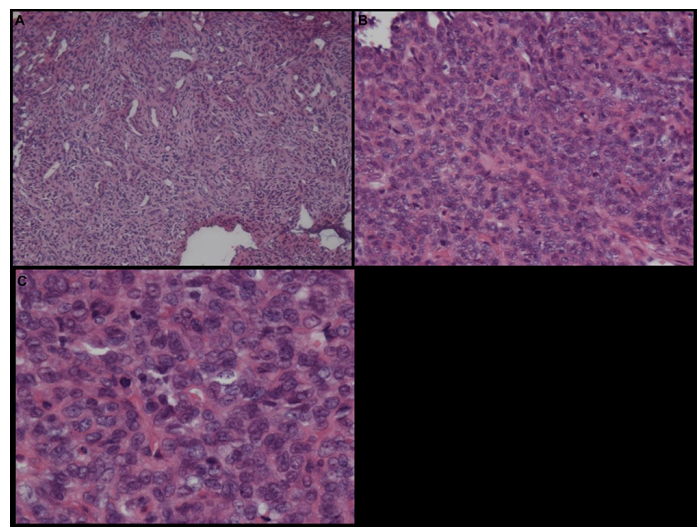

Figure 3 Histopathology. (A) Cellular tumour with thin-walled branching vessels showing a 'stag horn'like morphology. (B) Tumour cells with elongated nuclei showing moderate pleomorphism. (C) Higher magnification. Numerous mitotic figures are identified. 


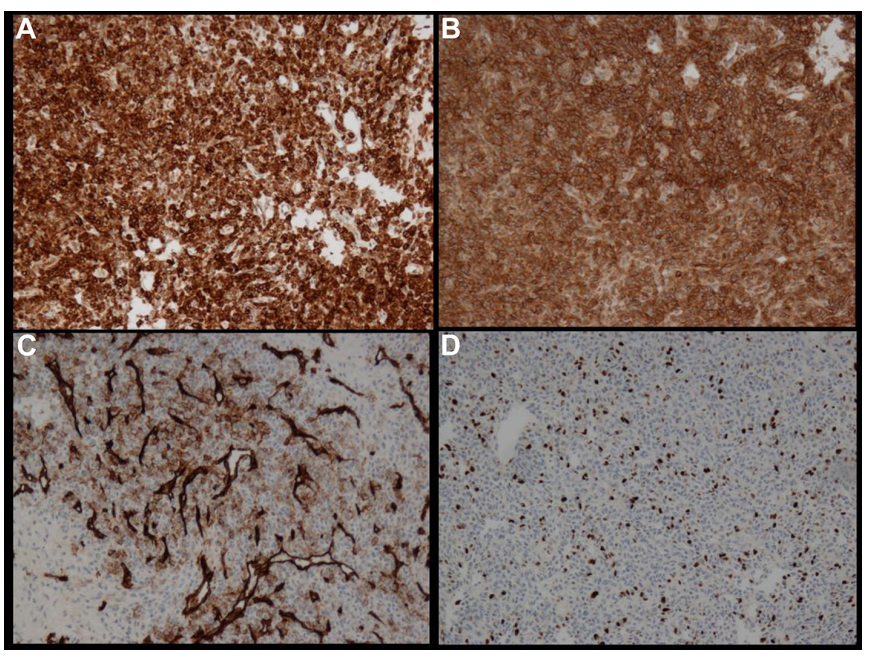

Figure 4 Immunohistochemistry. The tumour cells show strong expression of bcl-2 (A), CD99 (B) and CD34 (C), highlighting the vascular stroma and occasional tumour cells. MIB1 (D) shows a high proliferation index.

Postoperative recovery was uneventful with no residual neurological deficits. A CT chest/abdomen/pelvis was performed, which did not show any primary cancer elsewhere. The EVD was removed after 72 hours. The patient was discharged after 7 days. A postoperative MRI showed an enhancing dural-based lesion in the posterior fossa on the right side, with some residual haematoma (figure 2). Histopathology showed highly cellular tissue with striking vascular stroma, with some areas showing a staghorn-like morphology. The tumour cells showed significant nuclear pleomorphism and numerous mitotic bodies (figure 3). The tumour cells showed strong expression of bcl2 and CD99, with focal expression of both pancytokeratin and CD34 (figure 4). There was strong nuclear expression of STAT6 (signal transducer and the activator of transcription 6)_(figure 5), the STAT6 nuclear localisation being a consequence of the NAB2-STAT6 fusion, a genetic hallmark of the SFT/HPC group of CNS tumours. Carcinoma, melanoma, lymphoma and neuroendocrine markers were negative. There was no evidence of underlying vascular malformation.

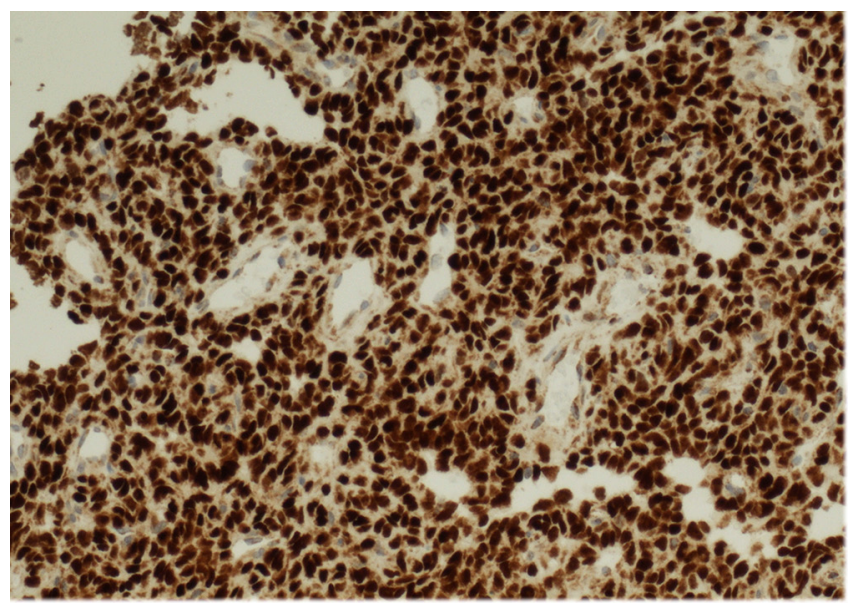

Figure 5 Nuclear expression of STAT6 (signal transducer and the activator of transcription 6) throughout the tumour, consistent with NAB2-STAT6 fusion.

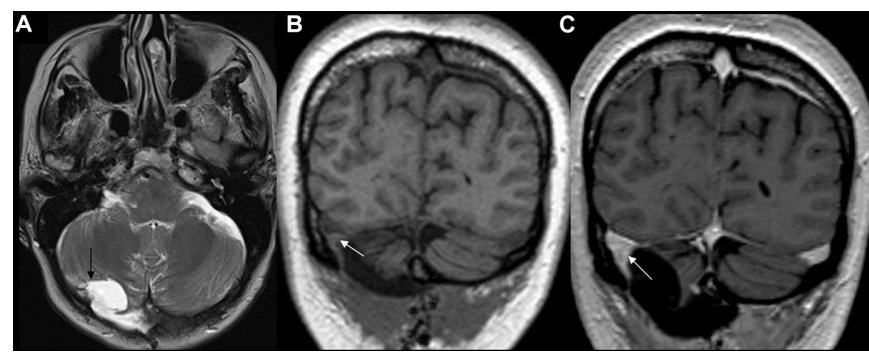

Figure 6 Second postoperative MRI: (A) T2 axial and (B,C) T1 precontrast and postcontrast coronal images. Postoperative cavity (black arrow in A). Small residual component (white arrow in $B, C$ ).

The histological appearances and immunohistochemical profile were considered typical for anaplastic HPC grade 3. Three weeks later, the tumour was excised, followed by postoperative adjuvant radiotherapy. The patient made complete clinical recovery with no neurological deficits. Further postoperative MRI (figure 6) showed a potential small residual component adjoining the right transverse sinus, which was stable until 1-year follow-up.

HPC is distinguished by a relatively aggressive biology showing a propensity for both local recurrence and extraneural metastases, which may appear even many years after initial diagnosis. ${ }^{4}$ The relatively fast growth rate of HPC is responsible for earlier presentation. Common presentations of cranial HPC include headache (50\%), seizures (33\%) or focal signs. ${ }^{5}$ Although quite vascular, they uncommonly present with bleeding, and the mechanism of which is unclear and does not seem to be affected by independent factors such as age, gender, size or location of the tumour. ${ }^{5}$ With dynamic classification, an accurate histopathological diagnosis is crucial for patients' counselling, management planning and overall prognosis. Intracranial SFT/HPC should be included in the differential diagnoses of dural-based haemorrhagic intracranial lesions, particularly when no primary tumour is identified elsewhere.

\section{Learning points}

- Haemangiopericytomas (HPCs) are rare intracranial vascular tumours that can occasionally present with haemorrhage, and these should be included in the differential of duralbased haemorrhagic masses.

- They have an evolving WHO classification, currently classified as mesenchymal non-meningothelial tumours combined with solitary fibrous tumours and graded 1-3.

- They have distinct histopathology and immunohistochemistry, which are important in deciding management and ascertaining their long-term prognosis, since they can have an aggressive biology.

Contributors The authors have contributed to the images/written material of this paper. AKK provided radiology images and CS provided pathology images; these constitute the bulk of the manuscript, which is in an images-only format. MA, KB and EB provided clinical details and information on clinical and surgical aspects. MA, $\mathrm{KB}$ and AKK provided the concept of case report. Inputs from all authors constitute the written component of the case report.

Funding The authors have not declared a specific grant for this research from any funding agency in the public, commercial or not-for-profit sectors.

Competing interests None declared.

Patient consent Obtained. 
Provenance and peer review Not commissioned; externally peer reviewed.

(c) BMJ Publishing Group Ltd (unless otherwise stated in the text of the article) 2018. All rights reserved. No commercial use is permitted unless otherwise expressly granted.

\section{REFERENCES}

1 Fountas KN, Kapsalaki E, Kassam M, et al. Management of intracranial meningeal hemangiopericytomas: outcome and experience. Neurosurg Rev 2006;29:145-53.
2 Louis DN, Perry A, Reifenberger G, et al. The 2016 world health organization classification of tumors of the central nervous system: a summary. Acta Neuropathol 2016;131:803-20.

3 Brunori A, Delitala A, Oddi G, et al. Recent experience in the management of meningeal hemangiopericytomas. Tumori 1997;83:856-61.

4 Alén JF, Lobato RD, Gómez PA, et al. Intracranial hemangiopericytoma: study of 12 cases. Acta Neurochir 2001;143:575-86.

5 Fredriksson F, Nordborg C, Hallén T, et al. Haemangiopericytoma presenting with acute intracerebral haemorrhagea case report and literature review. Acta Oncol 2013:52:753-8

Copyright 2018 BMJ Publishing Group. All rights reserved. For permission to reuse any of this content visit http://group.bmj.com/group/rights-licensing/permissions.

BMJ Case Report Fellows may re-use this article for personal use and teaching without any further permission.

Become a Fellow of BMJ Case Reports today and you can:

- Submit as many cases as you like

- Enjoy fast sympathetic peer review and rapid publication of accepted articles

- Access all the published articles

- Re-use any of the published material for personal use and teaching without further permission

For information on Institutional Fellowships contact consortiasales@bmjgroup.com

Visit casereports.bmj.com for more articles like this and to become a Fellow 